\title{
Restoring the Balance Violence and Culture among the Suri of Southern Ethiopia
}

Jon Abbink

'This country is spoiled now ... there is nothing to be said anymore. Suffering, we will perish, this country has become dark.'

(Last 1995: 153)

\section{Violence as a Problem}

Violent action is social behaviour and can be more fully understood in a theoretical perspective which sees humans as social animals with a capacity for symbol manipulation and social construction of 'meaning'. This capacity is a dimension of human behaviour which enters into the very definition of reality itself by both subjects and observers. When this perspective is combined with a sociological-historical theory based on Weberian ideas about power and legitimacy, it might also be able to deal with the ambigutty of the manifold social actions that in most societies can be labelled as violent. Ambiguity refers here to the very divergent evaluation of action based on harmful physical force. Few if any societies are consistently 'pacifist' in rejecting all violent action; in some conditions it is seen and experienced as necessary, inevitable, justıfied, or even psychologically rewarding.

In this chapter I examine the construction and expression of violence among the Suri (or Surma) of southern Ethiopia, a pre-literate, nonindustrial society of agro-pastoralists at the margins of a state society. This group does not share our (Hobbesian) model of man (being here similar to the related Mursi people, as claimed by Turton 1994a: 21). While in general terms the Suri cannot be called 'more violent' than, for instance, people in Western industrial society, theirs is a setting within which the workings of some elementary rules of violent behaviour in 
shifting cultivation of staple crops (maize and sorghum). Apart from cattleherding and cultivation the Suri are engaged in hunting. At the end of the dry season (March-April), there is a problem of water and pasture, with staple-food supplies running very low. They have both agricultural and agro-pastoral groups as neighbours.

The most prized possession of the Suri are their cattle-herds. Cattle do not provide more than about a third of the food supply (milk, blood, occasionally meat) but are a store of wealth which is necessary for establishing social bonds and marriages and which can also be traded for grain in times of need. In a cultural sense, the possession of cattle is also tied up intimately with ideals of Chai social personality, adulthood and individual dignity both for men and women (who also have rights of possession). Young men are expected to be committed to herding the cattle and defending it against raiding outsiders. On this basic level - i.e. that of their mode of subsistence and of 'competition for resources' - the readiness to confront and use violence (repulsing and/or killing the raiderenemies) is an essential requirement of the Suri way of life, and is not seen in any sense as problematic or contested.

\section{Internal Relations}

The Chai have no 'chiefs' but there is a ritual leader or figurehead, called komoru. The incumbent always comes from the same ancient clan. He is chosen by community consensus and installed by elders in a special ceremony. He has no executive or commanding authority when in function. His main role is to be a focal point of normative unity of all Chai. The British anthropologist D. Turton, in his work on the related Mursi (cf. Turton 1975: 180), has called the priest-like figure of the komoru a 'conductor of absolute power' (connected to the sky-god Tumu). The komoru is expected to emphasize values of restraint, to be non-violent, and to reconcile the various domestic units, clan groups and local communities if need be. ${ }^{2}$

The Chai also know an age-grade system, with four ritually separated grades of which the third one (called rórà) provides the 'reigning' one (age set) and has its own name. The initiated members of this grade provide the main decision-makers and authority figures. Women derive age-grade status from their husbands, and are not separately initiated.

Chai live in compact villages, with members from various clans. A clan identity is only important for the choice of marriage-partners (exogamy). Several villages form a territorial unit (called $b^{\prime}$ uran), which originated as a co-operative herding unit of its male members. Domestic units led by married women are the foci of social life. There is little units led by married women assions and wealth. Social relations outside stratification in terms of ritual bondfriendship (established through cattle-exchange), with other Suri as well as with non-Suri.

\section{Inter-ethnic Relations}

Chai society, both internally and in its relations to other ethno-cultural groups, is marked by frequent violence. Ambushes, robberies and killings groups, is marked menters of the different groups occur on a regular basis. These between members of the different groups occur on a regular basis. These 1993b, 1994). It is likely that external factors, such as the nature of state 1993b, 1994). It is likely that external the regional power balance, as well as the influx of technologically advanced automatic rifles have played a decisive role here. These factors, to which we return below, have partly disturbed the 'ritual control' of violence within Chai society itself. It can be claimed that Chai violence indeed always moved between the two be claimed that containment and palitical strategy. The former element was related to keeping equilibrium in their own society, the latter to was related to keeping equile water holes, fields, and other natural safeguarding access to pasture, water holes, fields, and other natura resources vis-à-vis other pastoralist groups (Nyangatom, Toposa and Mursi), and agricultural neighbours (Dizi, highlanders). In recent years there were additional political-ecological factors at play, and these brought them in conflict with the Anuak and the agricultural Dizi people as well them in conflict with the Abbink 1993a). Especially the relations with the latter, now their most immediate neighbours, deserve to be considered.

Historically, the Chai were located near Mt Naita (called in their language Shulugui), a border mountain between Sudan and Ethiopia. According to their oral traditions they were formed there or 'arrived' in According to their oral trad years ago. However, in the past decade, the Chai gradually filtered into areas formerly used by the Dizi people for cattle-herding, hunting and apiculture. The Dizi were an hierarchical chiefdom society, with elaborate rank distinctions. Since the early twentieth century they were heavily exploited by the northern Ethiopian settlers, and their numbers dwindled. Relations between Dizi and Chai are important for two reasons: a) both Dizi and Suri traditions maintain that their leading families share common descent and cannot intermarry; b) historically, they instituted a kind of ritual alliance in matters of raincontrol. While the Chai (and Tirma) leaders (komorus) were recognized as the rain-making powers in the lowlands, the final authority on this 
was ascribed to the Dizi chiefs in the adjacent mountains (see Haberland 1993: 253). Under this 'rain-pact' itself, the Cha1 - in times in drought, food shortage, cattle disease or other problems - were permitted to enter the areas claimed by the Dizi. This important cultural agreement was a kind of temporary sealing of a balance between these groups, and might be seen as codifying the exploitation of different but partly overlapping and complementary ecological niches. There was - and still is - economic exchange between them (cattle, pottery, iron products, grain, garden crops), and also frequent inter-marriage, although mostly in the form of Chai men talking Dizi wives: in itself a sign of Chai dominance. ${ }^{3}$

\section{Suri Culture and the 'Ethos of Assertiveness'}

It was noted above that on the level of the Chai mode of subsistence and the readiness to confront raider-enemies, violence is emphatically present. Violent action - raiding, ambushing killing enemy raiders and their dependents - is not seen in any sense as problematic or contested. But the Suri attitude towards violence is more than just essential self-defence. An imagery of tension and of violent confrontations, with the use of force and aimed at domination, is woven into many aspects of Chai life: into ideals of manhood or social personality, and in general in a ritually expressed concern with what we might call 'expansive reproduction': the growth of herds and of family and offspring. For outsiders, this attitude is reflected in many cultural metaphors which permeate Chai (Suri) culture (culture we define here as the more or less durable, shared and transmitted patterns of behaviour in which collective ideals and norms of a group are expressed and which form an element of identity formation), and even in the self-name 'Chai', which means: 'We revenge, we pay (them) back'. For the Chai themselves, this imagery or symbolism of 'violence' does not count as problematic either

We immediately note two things: first that this 'violent imagery' is mainly an aspect of the construction of the male gender. Females, while sharing the values underlying it, are not socialized to perform it except in a verbal manner. Second, we see that this imagery or symbolism is not seen as problematic or as referring to 'violence' by the Chai themselves. This is done only by external observers who are not part of the culture and who are not involved in the system of local group relations focused on cattle-herding and collective self defence.

The various realms of social discourse which serve to construct shared cultural scenarios for the Chai-and which are even shared in outline by their agro-pastoralist Nyangatom neighbours, very similar to them in way of life - might also be said to have psychological aims. first, to force new members of society to overcome the fear of violence, of armed attack, of wounding and killing. Interestingly, Chai say that young boys have to learn to suppress a 'natural inhibition' against the spilling of blood and against violently inflicting harm on others. A second aim may be to inculcate the idea of the immanence of violence, i.e. death, or the flowing of blood, in various stages and crucial moments of the life-cycle. When these two aims are achieved, violence is both domesticated, 'embodied', and made instrumentally useful (see following section).

This violent imagery is expressed in at least the following three cultural metaphors/schemas, which tell us about the indigenous Chai conceptions about human motivations and relations. These are important to consider if we want to advance theorizing about violence and warfare and their relation to culture (cf. Turton 1994b: 25).

The sacrificial metaphor: the equation of the killing and offering of a consecrated (domestic) stock animal with beneficial effects for humans. This is done at certain ceremonial occasions, for instance: marriage, burial, age-group initiation, a rain-ceremony, installation of a komoru, and also at a major public debate, or sometimes in case of serious illness. (As in most pastoral societies, cattle meat is hardly eaten outside a ritual context). The core ideas behind putting a consecrated animal to death are perhaps: substitution and vicarious victimization, because the violence is performed for the benefit of the human sacrificers. Maurice Bloch (1992) has called it 'rebounding violence', whereby the 'vitality' of a live being once killed ritually is deflected towards humans (utilized for human purposes). The effectiveness of the sacrifice is predicated upon the close (social) bond between humans and domestic (livestock) animals. The cattle also provide the bride wealth, and thus the medium for marriage and, ultimately, fertility. The flowing of blood thus is essential, yielding beneficial results. The idea of sacrifice was also relevant in the context of inter-group relations (see below).

The purfication metaphor: the idea of purification is pervasive in Chai culture. People involved in homicide or in handling corpses at burials but also in adultery are to be temporarily isolated and cleansed. They can only be made 'normal' members of society again by cleansing themselves with the freshly spilt blood of a stock animal. To purify, in this respect, means to kill and to transfer something of the life-force of the animal which was killed. Humans only then are able to re-enter social life. At the same time, to purify with the fresh blood is to redraw a boundary between individuals who were earlier socially separated by their violence, seen as a transgression. 
The achievement metaphor: a Chai's personal history or social career is important. His/her personality and deeds may live on beyond the lifespan, and in this awareness, people try to make a name for themselves, as 'warriors', ceremonial duellers, public speakers, important family heads, or ritual experts. Achievements are often reflected in personal favourite-cattle songs (roga kiyogá bio) or battle songs (kirogeñyò), which every adult male has. They are composed by men in the junior age-grade (tègay). Most men keep working on such songs during their whole life, changing and adding text. Such songs can speak of deeds done in raids and war, in other dealings with neighbouring and/or enemy peoples, and of actions carried out during the defence of cattle herds and of their own favourite animals. Violent moments or episodes are an inevitable and desired element of such achievements.

Another moment of achievement is, of course, gaining social adulthood. This adulthood is not 'just there' when people come of age, but must be achieved by having shown valour and personal strength (demonstrated in ceremonial duelling, see below), by capable herding, and by going through initiation (by retiring elders) into the senior age-grade For this, they must have demonstrated their being worthy of it. This is a function both of time passing and of appropriate behaviour of the junior grade (see Abbink 1994, 1998). Hence, adulthood cannot just be taken it is only reluctantly accorded to the newcomers by the outgoing elders. The ritual of the initiation has 'violent' aspects (i.e. physical harm is involved): elders (both men and women) insult the new candidates, give them exacting and humiliating tasks to do, deprive them of food, and lash them with whips until their backs bleed.

These domains reveal underlying values and violent motifs active in the constitution of the Chai social person, especially $v i s-\grave{a}$-vis outsiders. In their turn, these motifs and values inform cultural scenarios in Chai society. Linger (1992) has used the concept of 'cultural scenario' to indicate the expected behavioural 'performances' of values in action. For him, the briga, the violent street-encounter in Brazilian urban society, follows a known, shared 'scenario', a scripted course of meaningful action in which the participants know what to expect. It is marked by emotional commitment and shared assumptions and values. Even though the actions are violent and can end in death, they are set in a model, which has psychological and cultural components inhibiting direct aggression but communicating its message. The important point is that briga violence, although ambivalent because of its two poles of fascination and restraint, is not aimless, chaotic violence which suddenly erupts. A similar point can be made for Chai violence, which also follows cultural scenarios.

\section{The Exercise of Violence}

In this section, the practice of violence, i.e. the production and enactment of some frequent 'violent' behavioural patterns ('scenarios') in Chai society is reviewed. Two kinds could be distinguished: the ritually enacted 'domesticated violence', and the external violence, i.e. relating to nonChai. In the first instance, violence is transformative, i.e. fulfils an essential role for individual Chai in becoming full or accepted members of society; in the second instance, it is constitutive of their own group, a necessary inversion of peaceful social relations in certain conditions requiring distance between them and others.

\section{Ritual Enactment of 'Domesticated Violence'}

One finds the following forms expressed within the Chai group.

- Duelling (thagine) ${ }^{4} \mathrm{~A}$ major event of domesticated violence is male ceremonial duelling. This is done with big poles made of tough wood, of $c a$. 2.10-2.40 metres length. The main contestants are young men of the tègay age-grade (unmarried) coming from different territorial settlements and/or clans. They hold several matches and return-matches over a period of a few months every year, supervised by referees (oddá). The thagine-duel is strictly contained by rules of procedure, and the killing of an opponent, on purpose or accidental, is prohibited. If it occurs, homicide compensation should be negotiated. Social relations are perceived to be disturbed between the family groups of victim and killer as long as a deal is not made.

Three aspects of these duels stand out. First, the thagine ostensibly is a forum for male competition and acquisition of culturally approved status among peers and also vis-à-vis girls. They allow young, ambitious men, eager to start life as independent household-heads, to show their strength and virility. This latter aspect is explicitly recognized by nubile Suri girls: the duelling provides a place of male - female contacts, whereby girls among themselves make a first choice as to whom their partners might be, although there is no correlation of being the winner and being the most popular person. Second, it can be interpreted, in psychological terms, as a training ground for youths to explore the fascination and energy of violence in a controlled manner. Thirdly, the duels are forums where competing village communities within Suri society meet (People from the same village can never compete). On these occasions, where thousands of people gather, these communities (called $b^{\prime} u r a n$ ) are in fact constituted.

$$
-85-
$$

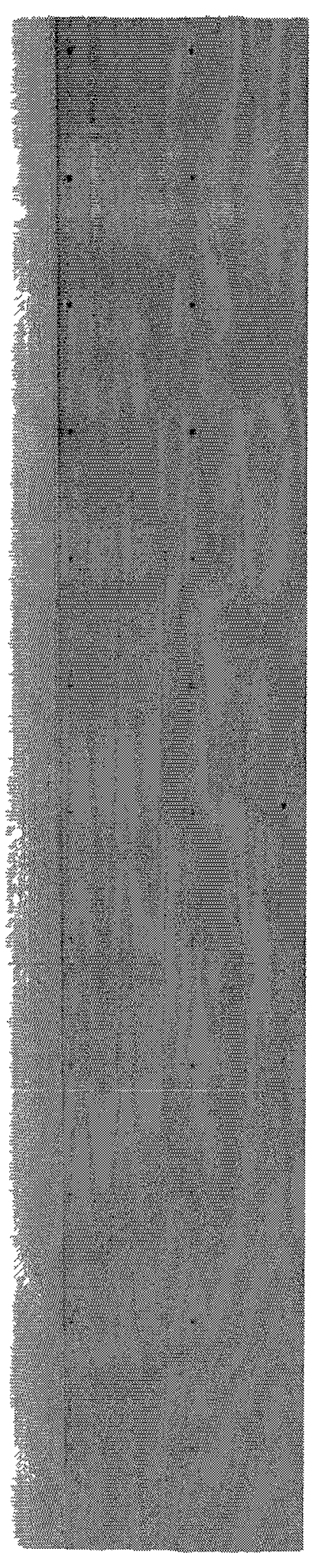




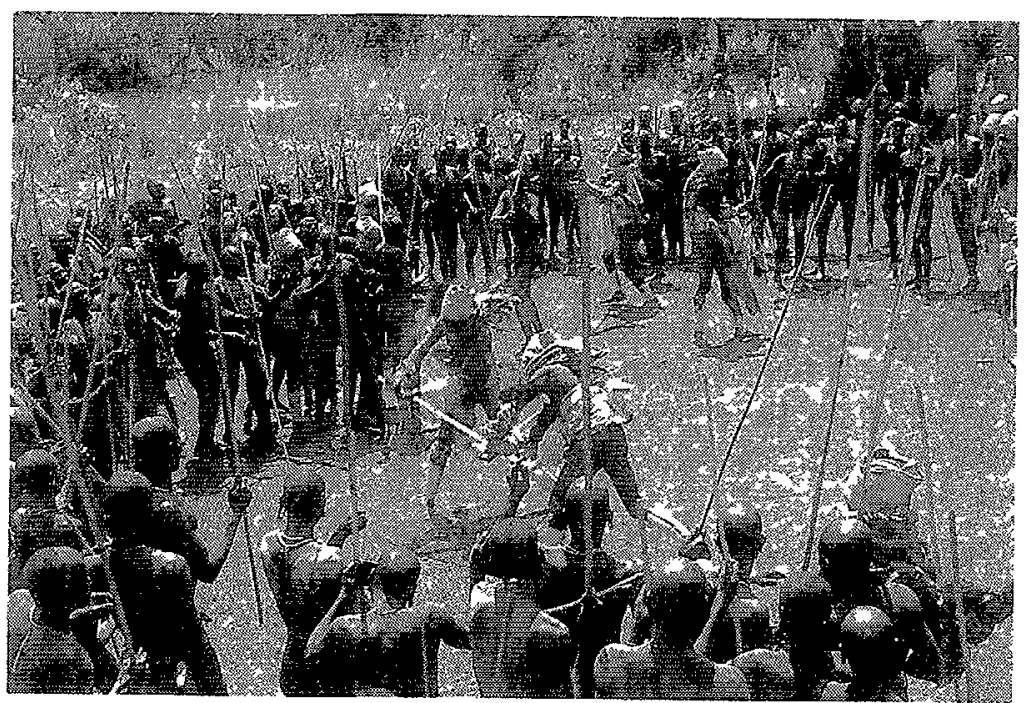

Figure 1. Cha1 duelling in progress

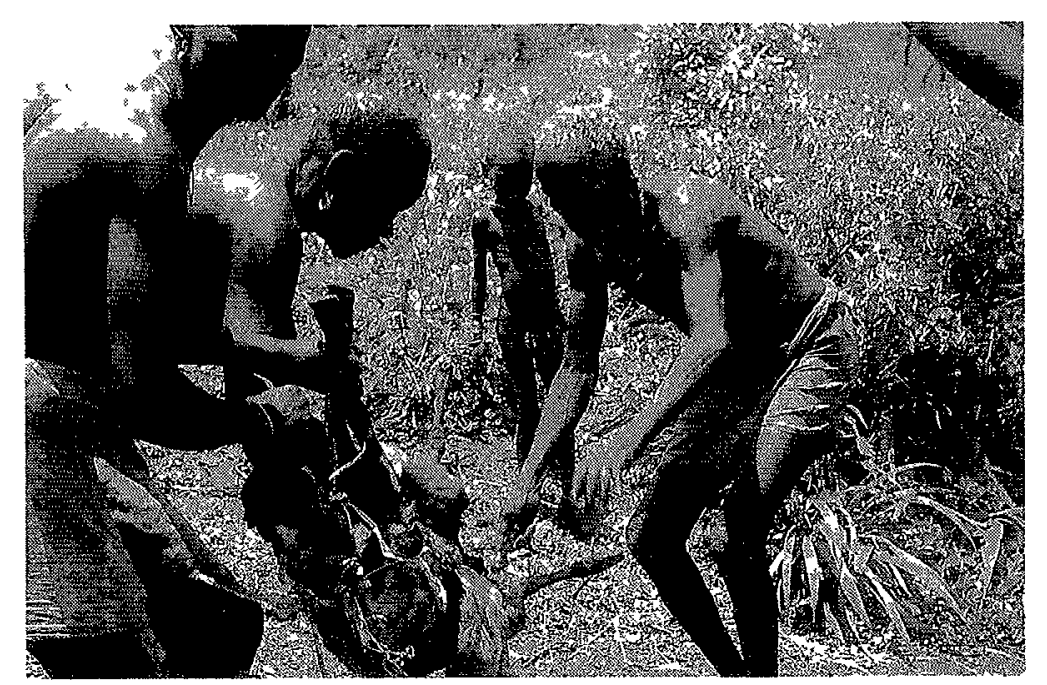

Figure 2. Spilling sacrifical blood in a homicide purfication ritual cuttıng open a live sheep

and the blessings of the komoru are full of violent imagery, cursing the enemies, calling upon the raiders to be fearless and dauntless in their attacks. They are expected to make effective use of violence and to come back with glory (They announce their 'successful' mission upon return in their village with a special boasting song). In the knowledge that the opponents do exactly the same, there is here again no controversy on the use of violence.

- The ritual killing of livestock (nitha). This is a very common event violent although not directed at humans. It is done when people have killed some one (on purpose or by accident), at an initiation-ceremony, a divinatory intestine-reading, a marriage, or a burial. The ideas of substitution and of cleansing through blood and death come back here. The manner in which the cattle or sheep are killed has its own meaning, but is seen as cruel by outsiders: it varies from cutting the throat, or slowly bludgeoning an animal to death (cattle), to slitting open the stomach before it is dead (sheep).

- Body culture. One could see certain Chai body treatments as violent, though they are again not 'contested' (except by government agents, who discourage it): the piercing of lips and ear-lobes with sticks and inserting big wooden and clay discs; the making of scarifications with 
a razor blade on the arms, back and abdomen of women; the kicking out of lower incisors with a stone, and the 'honorific' rido-scarifications (carved in the skin by an age-mate) for people who have killed. In all these cases, blood flows and pain is inflicted, but only in order to enhance culturally styled personal purposes: respectively aesthetics, age status, and personal achievement and prestige in the eyes of peers. It is not seen as a contested infliction of harm. This is all part of the self-conscious cultural body aesthetics which Chai emphasize vis-àvis other groups, and which is, for instance, completely lacking among the Dizi people.

\section{External Violence: Ritual and Political}

We have seen that the Chai had social relations of exchange, ritual friendship bonds (laale), and of joint exploitation of pasture and water resources with their Mursi, Nyangatom, Dizi and other neighbours. These groups had close social relations with them, which were fully taken for granted. But, with the exception of the Mursi, such groups remained outside the Suri 'moral community'. As the complementary side of these close social bonds, the Chai always knew various forms of violent behaviour and conflict in their dealings with them:

- The stealing of crops and individual cattle without violent assault. These matters, if the culprits could be found, were resolved through talks and compensation on an individual or family level.

- Ambushes, to kill an individual or traveller from another ethnic group either to rob grain, clothes, tools, a gun, or cattle, or just to kill to prove personal 'courage' (by a tègay, a junior age-grade member).

- The raiding of enemy cattle camps or compounds, with violent deaths of both defenders and attackers. These were short hit-and-run raids, with a brief and intense attack under a barrage of rifle-fire and a quick retreat.

- Occasionally: destructive one or two-day battles to destroy enemy settlements or wipe out its people. This was battle-warfare (kaman), and was the most serious form of violent interaction between two ethnic groups. Chai have had such fights with all their neighbours, except the Mursi. The purpose in such large-scale attacks was not only to steal cattle, but also to capture women and children, who were then incorporated in Chai society. While the violence used was intense and often deadly (hacking with knives and spears, shooting at close range), forms like rape or torture of the adversaries were, however, unknown.
One notes that the context of this external violence may be partly 'resource competition' and partly political strategy: the (re)drawing of group or territorial boundaries between political units. They do not fight because they are 'separate groups', but the reverse: in order to become so. This also holds for the Chai in their dealings with neighbouring groups (compare the same argument on the Mursi by Turton 1994a).

Relations with the agro-pastoralist Nyangatom were based on an implicit and recognized balance between two similar groups. They had a comparable acephalous organization and age-group system, a similar subsistence base, etc. Violence was a 'normal' social activity, not problematized as such. It also had a code of conduct: even in serious things like cattle-raiding, for instance, there was the rule of the preliminary marking (in the neck) of a few cattle from a targeted herd before the actual raid would take place. Conflict between the Chai and Nyangatom was, in sum, a way to express or assert a boundary with the 'significant other'. The killing of a Nyangatom allowed a Suri man to make the prestigious rido scarification on his arm.

With the agricultural Dizi people, who dominate the highlands northeast of the Suri and have a very different economy, culture and political ideology, relations were not based on perceived similarity. The Chai always had a disdain for the Dizi and their sedentary, agricultural way of life. But their obvious group differences - despite the myth of common descent of their chiefly families - were codified in an explicit 'contract' of rain control, based on the metaphor of sacrifice. In times of drought, the Chai would pay homage to the Dizi chief of the highlands, bringing a black ox and a black goat for sacrifice by the Dizi chief. The political tension (between two basically unequal groups) was 'appeased' in this agreement, thus keeping inter-group violence at bay through the metaphor of ritual sacrifice (substitutive violence). There were incidents between individuals of the two ethnic groups, but no major violent conflicts or battles. Neither did Suri apply the rido-markings.

The above elements shape the Suri practice of violence and define their habitus (in Bourdieu's sense defined as human dispositions acquired in society due to a process of internalization of external 'objective' social conditions). The habitus is also incorporated into action, feeling and thinking of individuals in a specific society, often in a quite literal sense, since the emphasis is on the bodily basis of these dispositions. This is also evident among the Suri. A habitus is, however, not static. 


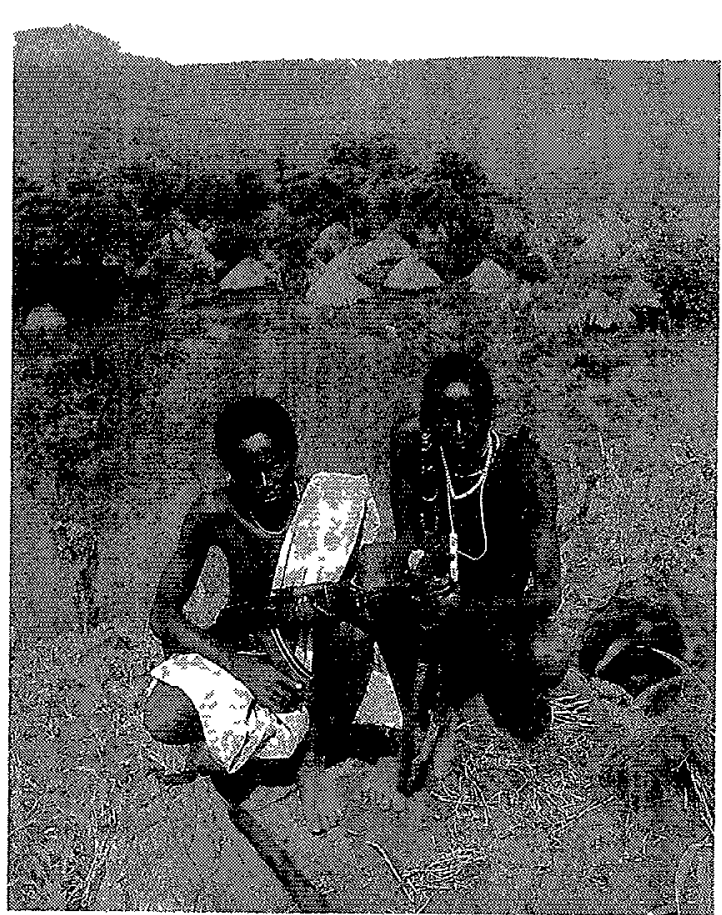

Figure 3. Wolektbo and Mesfin. two members of the tegay age-grade

\section{Transformations of the Violent habitus}

Since a decade, the face of violence among the Chai and their neighbours has changed in some important respects. Although the traditional situation of 'normal' relations between the ethnic groups in the area was not so harmonious as oral tradition asserts and therefore should not be glorified, it is apparent that the past years have shown a serious crisis in inter-ethnic relations. This kind of situation of local crisis and increased violence is seen general in many parts of Africa, due to internal and external factors (often in the context of globalization processes), bringing together various spheres of interaction and articulating conflicts of interests. Traditional rituals and customary law usually cannot achieve what they were designed for in bygone days. Local societies are structurally unable to maintain their integrity and moral fibre, due to drought and famine, population pressure, faulty state policies, tourism (see Abbink 1999), modern educatıon and new criminal activities.

As a result of recent political and other changes in the Maji area, both the internal 'ritual' Suri violence as well as the violence towards other groups tend to break the bounds of custom and to turn into the uninhibited use of force (This was also the opinion of the Chai elders, though expressed differently). While this use of force makes new options available for local people, it also tends to endanger the co-existence of groups as well as the peace in Chai society itself. Relevant factors have been population movements in the Ethio-Sudan border area due to the Sudanese civil war, increased local conflicts about pasture and water holes, periodic drought and famine, epizootics, a temporary retreat of central state authority from the local scene (especially in 1991-3), and generational conflict among the Suri.

All this was coupled with the rapid spread of automatic weapons among all groups, which changed the extent and intensity of violent encounters (see below). These factors have contributed to more inter-group conflicts, a decline in market contacts and a virtual halting of shared use of the environment and of mutual social contacts (including intermarriage and ritual friendship bonds). A three-year record that I kept of violent incidents between the Chai Suri and the Dizi (leaving out the conflicts which either group has had with another neighbouring population), shows at least sixty incidents with a fatal outcome, the number of people being killed ranging from one to several dozens per case. (With other ethnic groups like the Anuak and the Nyangatom the Suri also have violent conflicts, but due to geographical separation between them, the number of confrontations and of casualties has been less than with Dizi and highland villagers).

One of the problems to explain is why violence 'got out of hand' and led to a break-down of social relations between the Chai and other groups. Is it because their cultural models and their habitus were, in a sense, 'violent'? In the course of the conflicts with the Dizi, one can see a qualitative difference in the view on, and exercise of, violence, especially among the members of the tègay age-grade (see Abbink 1994): violent action - attacking and killing - became an aim in itself, a medium of self-glorification and of personal status which, while based on assumptions and ideals within Chai society, has gone well beyond them. ${ }^{6}$

To understand why this happened, we recall two general factors. First, the Chai subsistence base. They are transhumant herders and shifting cultivators, not sedentary farmers: they have never invested in long-term agricultural adaptation but in mobile cattle-herding. For them, boundaries 
between 'territones' and 'resources' are not to be strictly observed, it is against the nature of their open economy and flexible 'membership policy'. If such a closure occurs, due to conquest and exclusion policies (e.g. of Nyangatom, due in its turn to population growth and also Kenyan military pressure) or to developments of 'sedentarization' and administrative boundary-making, violent conflict cannot but increase. This is what has happened in the past decade. There is less and less room for Chai to follow traditional strategies of conflict resolution: avoidance, migration, or division and territorial spread of groups.

Second, the process of state expansion in the Maji area. Since the turn of the century, when it was nominally incorporated into Ethiopia, Maji has always been a 'frontier area', incompletely administered and on the margins of the state monopoly on violence. Recent efforts to re-establish the state after the change of regime in 1991 have 'problematized' all expressions of Suri violence. The state is by nature presenting itself as the normative, overarching authority which should have the exclusive use of legitimate force as well as combat 'harmful customs'. Local violence of Chai or of any other group is proscribed, regardless of its context (this was already the case under the previous state-communist regime of Mengistu). The state representatives have also, at various points, tried to prohibit many Chai activities or customs: not only cattle-raiding, ambushing, etc., but also the more innocuous things like animal sacrifice (the killing of cattle for divination or funerals), the customs of ear- and lip-plates, removal of lower incisors, and body scarification (These were called 'harmful customs' in the 1987 constitution of the previous regime, a concept which returns in the policy documents of the post-1991 government). Recently, in 1994 and after, it was also tried to ban the ceremonial duelling contests.

It is obvious that this so-called 'civilizational offensive' represents an assault on the socio-cultural fabric of Chai society. As the Chai are held responsible for most of the violence in the Maji area, state officials think that by reforming the what they see as overall violent character of Chai culture they can halt violent conflicts. It is, however, likely that if this state campaign to 'reform' Chai culture - by banning the customs just mentioned - would be successful (it is not), the violence against nonChai would notably increase when these domesticated forms of violent expression would cease to exist. In addition, while the state discourages or forbids even Chai self-defence and redressive action against enemy raiders, at the same time it cannot guarantee defending the Chai and their territory against such raiders (e.g., from the south or from Sudan), nor protect them from drought and subsistence crises, factors which necessitate at least some violent action. More immediately important factors stimulating the overall use of violence have been:

1. The wide availability of automatic rifles and ammunition from both Sudanese and Ethiopian sources.

2. Continued ecological pressures: drought, cattle disease, more scarcity of bush land for cultivation and pasture for livestock. There was a major famine in 1984-5 and again one in 1994, and in early 1997. This contributed to theft, ambushes and raiding.

3. The conflict in southern Sudan, which became the source of population movements in the region, pushing the Toposa to the western borders of the Suri territory, thus making their pastures and their old ritual sites, chiefs' burial places and settlements unsafe, and posing a threat to their cultural and also physical existence.

The effect of such changes in the socio-political and physical environment on the Chai, and on their use of violence in their relations with other groups, has been dramatic, although it is not a one-way causal chain - the developments in their own society have combined with such external factors to reinforce crisis and violent conflict.

It could be seen most clearly in the crisis in the age-grade system, which is the core of their political organization and internal order (cf. Abbink 1994; 1998). In the age-grade system, the elder or reigning ageset of rórà is to be accorded respect and obedience from the younger one. They occasionally expect to be honoured and, in a metaphorical sense, 'fed' in recognition of that fact, e.g. by being offered sacrificial cattle. Their blessing of the land and the cattle and their authority on the basis of age is seen as a necessary element in the social order. But it was resented by the reigning age-set called Neebi (= 'Buffaloes') that the tègay were always taking violent initiatives on their own, not sanctioned by public decisions at meetings. The tègay, mostly younger herders who lived in the cattle camps (in an area six hours' walk from the villages), could assert themselves because of the power of their rifles and on their growing economic leverage (as herders and as gold traders: see Abbink 1993a). Also in other domains the respect of the younger generation toward the elders and parents was diminishing, even within families: personal property and heads of cattle were often taken away by youngsters, without the consent of the parents.

The growing violence perpetrated by Chai youths initially convinced Chai elders (who control the date and the proceedings) that the new ageset initiation, which was already due in the early 1980 s, should be delayed. 
With this, they expressed that the Cha1 first should formulate an answer to their problems, such as being exiled from their country, recovering from the drought and famine perod in the mid-1980s, running into trouble with the Dizi and the Anuak (which endangered normal social relations and trade), and not respecting the elder generation. The tègay were blamed for all this, and the elders did not have a clear answer to the problems. The increased violence had brought out internal contradictions in the agegrade system and the authority structure and norms it was supposed to uphold. In fact the metaphor of age organization as a cultural model of ordering social life was fundamentally disputed.

The availability of automatic weapons, now acquired by virtually all men, led also to changes in the concept of violent action and to new violent practices. Above, we have discussed some core elements of the cultural basis of 'violent imagery' and action among the Chai. In the new situation, their values of male achievement and reputation, raiding and hunting exploits and ceremonial duelling provided a fertile basis for the expansion of violent performance by means of the new weapons, for instance:

- Compared to the spears, knives and old three or five-shot rifles of a generation ago, the possibilities of the Kalashnikovs, FALs and M$16 \mathrm{~s}$ seem to have a fascination and momentum of their own. Their availability not only leads to mimetic exercise of violent acts by the tègay vainly seeking recognition still structurally denied to them (see above: the delayed age-set ceremony), but also giving the possessors the idea of 'social self-sufficiency': they explicitly de-emphasized the value or even the need of normal social relationships as formerly maintained with the neighbouring groups.

- The weapons also have been put to new use. For example, there have been some unprecedented instances of Chai killing their own cattle to prevent it from being captured and taken away by enemy raiders (This has also been observed among the Tirma, and among other newly armed pastoral groups in Uganda and Kenya, the Pokot, Turkana, Karimojong, etc.). The reason given by the Suri herders of this highly controversial and much debated 'innovation' in violent practice is that the Nyangatom raiders hide between the captured cattle. There has also been the gunning down of Dizi elders and women and the killing of unarmed Dizi girls in ambushes, things not done in the recent past. Through this violence, exercised largely with impunity, the Chai and Tirma became more and more saturated with the feeling of power, and challenged not only the Dizi peasants but also the state army. This built up until October 1993, when a big Ethiopian army attack caused several hundred of Chai and Tirma (men, women and children) to die. Only after this obvious defeat, the elders decided to hold the age-set ceremony, initiating and conferring adulthood on the 'delayed generation' (see Abbink 1998). Since then, Chai Suri violence has decreased. The Tirma sub-group, which has not yet performed the initiation ritual, shows at present a higher level of violence than the Chai. Two other internal changes in Chai society are the following:

- In the past six or seven years, the institution of thagine, the ceremonial duelling, has undergone a metamorphosis. First of all, the frequency of the contests has much increased. They are held almost every two to three weeks over a period of three to four months after the main harvest of sorghum (September-November, and after that as well, e.g. in January and in the time of the first rains in April-May. Secondly, the influence of the elders (including the komoru) and the referees over the contesting parties has diminished: nowadays, the young men and their friends continue as they like, and after one party has 'lost' one contest, they grab their Kalashnikovs and start shooting (usually, but not always, in the air) to show their irritation. This had led to several accidental killings. One can hear the Suri elders say that the meaning of duelling is being eroded. We see here another cultural scenario in flux, whereby accepted meanings of 'violence' are transformed.

- There has been an increase in feuding: when a homicide is perpetrated, Suri seem to lose the patience to sit out the traditional compensation talks. The kin group of the victim, if strong enough, demands immediate damages, or else call for retribution. Such feuding conflicts also affected the family of the komoru. Among the Tirma-Suri, for instance, there has been a long line of killings between two lineages since one of their two komorus was accidentally shot dead: by a Tirma. This in itself is unprecedented.

The above forms of violent behaviour are now also contested within Chai society; elders, the komoru, and women especially talk against wanton violence against Dizi and other travellers, against unprovoked killing and robbery of former Dizi bond friends, and against the shooting at duelling grounds.

The changes in the exercise of violence both within and without Chai society points to major shifts of meaning. In fact, we see a movement from ritually contained violence to political and instrumental violence, the aims and meaning of which are less clear to everybody. There is a phase of deep uncertainty and sometimes fear, of a transition of meanings. There is an awareness that many of the tegay generation have abused the 
cultural norm of status acquisition on account of killing an adversary: this happened only in battle with recognized, long-standing enemies (i.e. not with Dizi and other highlanders except after manifest injustices). The tègay do it repeatedly, 'without a reason', and break the rule of restraint in violent behaviour.

\section{Concluding Remarks}

The Chai-Suri cultural style is marked by normative ideals of male personhood and peer status which accord value to assertive behaviour, which may translate into violent behaviour when material interests and competitive economic and social relations with other groups are involved. Suri culture can, however, only be called a 'culture of violence' reproducing violent behaviour as a template, an ideal or a habitus - in its relation to, or opposition to, those outside their moral community.

Chai-Suri expressions of violence have shown important modifications in recent years. While ecological and material conditions play a role in explaining this, an anthropological, cross-cultural understanding of the new dialectics of violent action needs to take into account how violent processes actually unfold on the basis of symbolic-cultural representations and how they establish meaning, either instrumental or expressive.

In a way, violence breaks the bounds of normative culture, and of the social system. The ritualization of violence is diminishing, and more unstructured and unpredictable forms emerge. We see here a society pushing against its own structural and cultural limits ${ }^{6}$ that where the result of the long process of social evolution. In relations with neighbouring groups (especially Dizi and Nyangatom), this Chai violence can still be seen as a 'language', a communicative act, but mainly one of intimidation. Violence in this sense 'bridges' the communication failures that have cmerged, but it grounds group relations in suspicion and fear - in the absence of shared frameworks of control (cf. the breakdown of the rainagreement with the Dizi and of the fighting code with the Nyangatom).

A more neo-functionalist explanation of violent behaviour, as offered in recent evolutionary approaches, seems of limited value because it tends to assume what has to be demonstrated in each empirical case (cf. Knauft's criticism, 1987/8, 1991). For instance, the interpretation of Chai violence seems to preclude an easy association between successful raiding or violent behaviour on the one hand and reproductive success on the other. Comparing census-material and involvement or prestige in raiding of dozens of Chai men did not give any meaningful correlation. The most important killers were not more popular with women and did not have more wives and children. Neither did they have larger herds. Certain rules make accumulation of this sort difficult: the captured cattle is being divided among all participants of a raid in a time-consuming and laborious procedure. Other facts which refute such a connection include the position of the komoru: he usually has a large number of wives and children and the largest herd of cattle, but he is noted for his reconciliatory and mediatory role, and his role-model de-emphasizes aggressive behaviour and aimless violence. We also saw already that in the thagine ceremonial duelling the victors are not the universally popular guys outshining the losers: all participants regardless of their place on the list of honour are esteemed.

What the examination of the Chai case suggests is that 'violence' is an essential, inherent part of social life, and need not be always be seen as a contested practice, in the sense of unexpected or 'irrational' behaviour towards others. This was true for the Chai and the Nyangatom - both with the same focus on cattle-herding, both with a stratum of 'warriorherders', and with the underlying idea that violent self-assertion, both in ritual and in collective defence, was inevitable, a part of life. When people were killed it was said to have been 'bad luck' for them, caused by, for instance, failing ritual protection. It was not contested in itself. With the Dizi it was different, but we have seen how the latters' perception of illegitimate, excessive Chai violence in recent years was partly generated by the breach of a previous 'historical contract', and by changing regional and state-local society relationships, where different forms of incorporation into overarching political structures and value systems (as expressed in the fight over the monopoly on the means and exercise of violence) of both groups led to regional discrepancies and conflicts. The violence against the Dizi is now also problematic among the Chai and is the issue of many debates (cf. Abbink 1998).

'Violent practices' of the Chai are a traditional concomitant of their evolved survival strategies as cattle-herders in a precarious natural and human environment. Their commitment to the herds - to feeding, defending, and expanding them - has led to a close socio-cultural bond between humans and cattle, symbolically elaborated in their cultural style and their values of social personhood and achievement. Violence is, however, not simply a 'selectively advantageous trait' of Chai behaviour. Their ideals and values certainly reflect a complex violent imagery, but at the same time a pervasive sociality within and beyond their society, suggesting that, on this elementary level also, both are inextricably linked. This again shows the ambiguity of violence as a category of social action: it constitutes and it undermines sociality, the latter especially when released form its cultural formulations. 
When the Chai mode of existence is becoming more precarious or even undermined, either by long-term disturbances in ecological conditions or in the inter-group and state relations puttıng them at a disadvantage, a recourse to more 'hard violence' will be likely. Traditional understandings between local groups then lose importance, the regional equilibrium is disturbed, and an overarching accepted state structure is not present. Also, the continued availability of modern weapons and plenty of ammunition has had a seductive effect on Chai young men, prompting them to use violence beyond any instrumental necessity. As we saw, this has led to serious internal contradictions within Chai society, and to decisive changes in traditional Chai meanings of violence.

In most of the situations which we presented, violence in Chai society can be seen as a means to symbolically construct a group identity, or 'we-consciousness' - it is not there automatically. This consciousness is based upon ideas of clan descent or affiliation, language, and a cultural aesthetics expressed in decorative customs, but forged into an enduring group identity - or at least into one valid for some purposes - within the network of competitive and exchange relations with other groups in the region. As such, violence is inevitable, a fact of life, and not in any sense problematic or destructive or an irrational regression to evil human nature. When we talk about the violent 'images' in Chai discourse, the usefulness of Riches' definition (see above) is limited: from a Chai point of view, much of their violence is not 'contestably rendering physical hurt', but only uncontested, legitimate self-defence, retaliatory or pre-emptive damaging of enemies, or beneficial sacrifice of animals, with which no one in that context would argue.

Finally, this question of violence being 'contestable' in local Chai terms would perhaps only arise when (a) according to the normative authority figures such as elders and the komoru the people, especially the younger generation, defy the rules and obligations and act on their own account thus changing or undermining the social order; (b) when new forms of aggressively violent and wanton cruel behaviour would appear, such as rape, torture, hired killing, or nihilistic destruction, well-known from (post)modern industrial societies. The possibility that such forms can emerge may not be precluded (as we know from cases elsewhere in Africa). Subjectively perceived economic exploitation, unbalanced state interference, artificially hardened ethnic boundaries, unsolvable problems of resource competition combined with factors like the easy new technology and power of killing (due to the spread of automatic rifles, hand grenades, and other small weapons) may prepare the ground for it. Also more intangible factors connected to the process of globalization, such as the penetration of a new cultural 'language' of visual images or of a fantasized reality evoked by imported Western or Asian violent videos, might enhance this process, as they can lead to internalizing new habituses of violent practice and performance (In the Suri country there is at present one rather unruly 'frontier town' where such videos are now becoming readily available, also seen by visiting Suri). This process may then invalidate - or at least transform - customary codes of restraint and social order ${ }^{7}$ as the Suri are gradually included in the globalized domain of 'displaced signs' and 'commoditized symbols' through the new media, tourism, Christian missionizing and imposed state modernization projects. The transformation of violence has been a multi-faceted historical development in Western (and other) modernizing societies. In recent years such a process has been occurring - though perhaps at a faster pace - in extraordinary situations of disturbance and upheaval in, for instance, Papua New Guinea, Mozambique, Liberia or Sierra Leone. The combined impact of the interference of the state (with its hegemonic project), the availability of automatic weapons, the new "video culture', ${ }^{8}$ and increased antagonism between competing groups (e.g. 'ethnic') might create a new discourse of violence. This would have an impact on traditional understandings of violent performance. What seems likely in any case is that more central state authority in the Suri area will transform cultural notions and patterns of violence but not cause the disappearance of violence itself.

\section{Notes}

Fieldwork among the Chai Suri in southern Ethiopia was done in 1991 94 with generous support from the Royal Netherlands Academy of Science (KNAW), the African Studies Centre, Leiden, and the Netherlands Organisation for Scientific Research in the Tropics (WOTRO, WR 52610), which I gratefully acknowledge. I also thank the Institute of Ethiopian Studies (Addis Ababa University) for institutional support, local officials and inhabitants of the Maji and Adikiaz area, and $\mathrm{Mr}$ John Haspels, representative of the EEMCY and LWF in Tulgit, Maji zone. I am most indebted to the Chai people of the Makara settlement. I benefitted a lot from the critical comments on a first draft of this paper from participants in the International Seminar on the "Ambiguity of Violence' at the Institute for Advanced Studies in Social Anthropology, Göteborg 
University (July 1995). This chapter is a revised version of a text earlier published in Cahiers d'Études Africaines (1998). I thank the Editoral Committee of CEA for their permission to use that article.

1. Violence is used here as in the definition given in the Preface of this book. Compare also Corbin (1977).

2. More on the authority structure among the Chai in: Abbink (1997).

3 . In the course of time, the Dizi - who also kept cattle in the lowlands came to adopt several customs related to the 'cattle-culture' of the Chai, but they never developed a comparable assertive ethos, emphasizing for example, personal violent performance, militant defence of the cattle herds, or a specific decorative 'body culture'.

4. In this and other sections I draw partly on material first presented in Abbink (1993a; 1994).

5. In the film The Mursi (1974, Granada TV, Disappearing World series, UK), the similar ritual among the Mursi, called 'spearing the priest', is shown.

6. In fact to such an extent that the cohesion of Chai society itself was endangered (see Abbink 1998).

7. Professor Bruce Kapferer rightly emphasized this point in discussion.

8. Its emergence and adoption in Africa should be investigated in detail. The negative effects of violent and sadistic videos after their displacement to, and appropriation in, other socio-cultural settings are grossly underestimated.

\section{Tolerating the Intolerable: \\ Cattle Raiding Among the \\ Kuria of Kenya}

Suzette Heald

\section{Introduction}

What does it mean to be a warrior? What does it mean to be a thief? Historically, the two are closely linked in the pastoral and agro-pastoral societies of Eastern Africa where political opposition was expressed largely through cattle raiding. The feud, as we learnt from Evans-Pritchard (1940), is a social relationship and a central social institution in such societies. Yet, the fate of these 'raiding societies' has diverged sharply in this century. To simplify, in the northern arid areas, Ethiopia, Sudan, Somalia and the northernmost parts of Kenya and Uganda, pastoral societies have been caught up in the maelstrom of wars. To the south, in the better watered areas, we get a contrasting pattern, of relatively stable state organization and an overall decline of the pastoral sector of the economy as crops have increasingly been produced for the market. Both developments have had a particular effect on the roles of young men. In the first group of societies, the military wing of the pastoral economy has become ever stronger as the weakness of the state and the influx of advanced weaponry has put a premium on defensive potential (Fukui and Markakis 1994). As these societies have become ever more bellicose, we hear of younger and younger men taking up arms to defend their groups or recruited into armies fighting nationalist causes. In the second group of societies, as raiding has lost its political valence, it has increasingly come to be regarded as common theft, a mark not of gallantry but of crime. It is these societies that have seen in the recent past self-help used not as an instrument for inter-group competition but as a means of intra-group control.

In January 1995, while doing fieldwork in Kuria in southwest Kenya I was given a lift to town by a Luo driver. The conversation turned, as did 